\title{
CRESCIMENTO DO Acetobacter xylinum (ATCC 23769) E A PRODUÇÃo DE CELULOSE BACTERIANA
}

\section{GROWTH OF Acetobacter xylinum (ATCC 23769) AND THE BACTERIA CELLULOSE PRODUCTION}

\author{
Denise Milleo Almeida ${ }^{1,3}$; Gilvan Wosiacki ${ }^{1,2}$; Guataçara dos Santos Junior ${ }^{3}$; \\ Elisângela Serenato Madalozzo ${ }^{2}$; Misaeli Maria Zanlorenzi ${ }^{3}$ \\ ${ }^{1}$ Universidade Federal do Paraná - UFPR - Curitiba - Brasil \\ ${ }^{2}$ Universidade Estadual de Ponta Grossa - UEPG - Ponta Grossa - Brasil \\ ${ }^{3}$ Universidade Tecnológica Federal do Paraná - UTFPR - Ponta Grossa - Brasil \\ misaelizanlorenzi@hotmail.com
}

\begin{abstract}
Resumo
Esta pesquisa teve como objetivo verificar o crescimento da biomassa da Acetobacter xylinum (ATCC 23769) com a produção de celulose bacteriana. O cultivo ocorreu em água de coco maduro (200 ml) na forma estática e em agitação (100 rpm) e com adição de diferentes soluções salinas $\left(\mathrm{NH}_{4} \mathrm{PO}_{4}, \mathrm{KH}_{2} \mathrm{PO}_{4}, \mathrm{MgSO}_{4} 7 \mathrm{H}_{2} \mathrm{O}, \mathrm{Na}_{2} \mathrm{HPO}_{4}, \mathrm{FeSO}_{4}, \mathrm{H}_{3} \mathrm{BO}_{3}\right)$, configurando 32 ensaios. Foram adicionados $5 \%(\mathrm{v} / \mathrm{v})$ ou $0,06 \mathrm{~g}$ de biomassa seca do inóculo com incubação a $30^{\circ} \mathrm{C} \pm 2^{\circ} \mathrm{C} / 24 \mathrm{~h}$, 96h e 168h. Para a remoção da biomassa o caldo de fermentação foi centrifugado a $7000 \mathrm{rpm} / 15 \mathrm{~min}$ a $4^{\circ} \mathrm{C}$, seguida de lavagem com água destilada e posteriormente levada à desidratação em estufa a $50^{\circ} \mathrm{C} \pm 5^{\circ} \mathrm{C} / 24 \mathrm{~h}$ até massa constante. Ao sobrenadante foi adicionada a proporção de solvente etanol $96^{\circ} \mathrm{GL}+$ acetona P.A. (1:1:2) para precipitação da celulose. Após $24 \mathrm{~h}$ de refrigeração procedeu-se nova centrifugação por 30 min para a recuperação da celulose. O precipitado foi lavado com água destilada e desidratado em estufa a $50^{\circ} \mathrm{C} \pm 5^{\circ} \mathrm{C} / 24 \mathrm{~h}$ até massa constante. A maior produção de biomassa ocorreu em cultivo estático entre 96 e 168 horas. Já para a produção de celulose, não se pode afirmar que exista maior rendimento entre o cultivo estático ou agitação. O microrganismo produz uma quantidade elevada de celulose nas primeiras 96 horas de fermentação seguida de um maior aumento na produção de biomassa.
\end{abstract}

Palavras-chave: biomassa, celulose, Acetobacter xylinum.

\section{Introdução}

Devido aos avanços da biotecnologia, vários estudos vêm sendo desenvolvidos para produção de polímero de origem microbiana, também chamados de biopolímeros (AQUINO, 2006). São também conhecidos como gomas ou exopolissacarídeos, que tem a capacidade de formar géis e soluções viscosas em meio aquoso (MOREIRA et al., 2003).

Entre os biopolímeros de grande interesse está a celulose produzida pela linhagem de Acetobacter xylinum. Suas aplicações na indústria de alimentos são: sobremesa (nata de coco, 
sorvetes com baixa caloria, lanches, doces); espessantes (sorvetes e temperos para saladas); bases para redução de peso; bases para alimentos artificiais; tripas para embutidos; soro para redução de colesterol (US patente 4, 960,763); elixir Kombucha ou chá Manchurian (BROWN apud SILVA, 2003).

Porém, as pesquisas acadêmicas, apresentam um rendimento baixo quanto ao volume de fibras de celulose (nata) produzida. Desta forma, há necessidade de novos estudos e experimentos na cinética do processo fermentativo buscando maior eficiência entre o crescimento do microrganismo, a formação do biopolímero.

Desta forma, a pesquisa teve como objetivo verificar o crescimento da biomassa da Acetobacter xylinum (ATCC 23769) com a produção de celulose bacteriana.

\section{Materiais e métodos}

O microrganismo utilizado no processo de fermentação foi o Acetobacter xylinum (ATCC 23769). O cultivo ocorreu em água de coco maduro (200 ml) na forma estática e em agitação (100 $\mathrm{rpm})$ e com adição de diferentes soluções salinas $\left(\mathrm{NH}_{4} \mathrm{PO}_{4}, \mathrm{KH}_{2} \mathrm{PO}_{4}, \mathrm{MgSO}_{4} 7 \mathrm{H}_{2} \mathrm{O}, \mathrm{Na}_{2} \mathrm{HPO}_{4}\right.$, $\mathrm{FeSO}_{4}, \mathrm{H}_{3} \mathrm{BO}_{3}$ ), configurando 32 ensaios. Foram adicionados $5 \%$ (v/v) ou 0,06g de biomassa seca do inóculo com incubação a $30^{\circ} \mathrm{C} \pm 2^{\circ} \mathrm{C} / 24 \mathrm{~h}$, 96h e $168 \mathrm{~h}$. O pH inicial do meio de cultivo foi ajustado para 5,0.

Para recuperação da biomassa e da celulose bacteriana adaptou-se procedimento descrito por ROTTAVA (2005), FORNARI (2006), BERWANGER (2005), LEE JIN (2001) no qual o caldo de fermentação foi centrifugado a $7000 \mathrm{rpm} / 15 \mathrm{~min}$ a $4^{\circ} \mathrm{C}$ para remoção da biomassa seguida de lavagem com água destilada e posteriormente levada à desidratação em estufa a $50^{\circ} \mathrm{C} \pm 5^{\circ} \mathrm{C} / 24 \mathrm{~h}$ até massa constante. Ao sobrenadante foi adicionada a proporção de solvente etanol $96^{\circ} \mathrm{GL}+$ acetona P.A. (1:1:2) para precipitação da celulose. Após 24h de refrigeração procedeu-se nova centrifugação por 30 min para a recuperação da celulose. O precipitado foi lavado com água destilada e desidratado em estufa a $50^{\circ} \mathrm{C} \pm 5^{\circ} \mathrm{C} / 24 \mathrm{~h}$ até massa constante.

Neste trabalho houve a necessidade de se obter a estimativa da média populacional, bem com sua margem de erro e estimativa de um intervalo de confiança para o rendimento médio de biomassa seca e para o rendimento médio de celulose produzido. Salienta-se que tais conceitos foram utilizados considerando pequenas amostras. Portanto, para as inferências realizadas foi suposto que a distribuições das populações das variáveis analisadas se apresentam em distribuição aproximadamente normal. 
Para obter a margem de erro e o intervalo de confiança da média populacional para as diversas variáveis analisadas, utilizaram-se respectivamente as equações (1) e (2) conforme TRIOLA (1990, p. 153) e foi utilizado nível de significância igual a 5\%.

$$
E=t_{\alpha / 2} \frac{s}{\sqrt{n}},
$$

Onde $\mathrm{t}_{\alpha / 2}$ é o valor crítico obtido da distribuição t de Student e tem n-1 graus de liberdade. Ainda a equação (1), s indica o desvio-padrão amostral e n o tamanho da amostra utilizada. O intervalo de confiança é obtido como segue:

$\bar{x}-E<\mu<\bar{x}+E$,

onde $\bar{X}$ é a média aritmética amostral, E é a margem de erro obtida pela equação (1) e $\mu$ é a estimativa da média populacional.

Também houve a necessidade do uso nesse trabalho do diagramas em caixa (boxplot) com a expectativa de revelar tendências centrais, a variabilidade dos dados e a presença de outliers (valores extremos). Para se obter os diagramas em caixa necessitam-se do primeiro quartil, terceiro quartil e mediana. Maiores detalhes sobre os diagramas em caixa podem ser obtidos em TRIOLA (1990, p.52).

\section{Resultados e discussão}

A produção de biomassa e celulose aumentou à medida que o tempo de fermentação foi se desenvolvendo. Comparando a quantidade de biomassa, durante o processo de fermentação, em cultivo estático e em agitação a 24h, 96h e 168h pode-se observar uma maior produção em cultivo estático. Entretanto, a melhor produção de celulose de 17,1g/200mL ocorreu quando a quantidade de biomassa chegou a $0,59 \mathrm{~g} / \mathrm{mL}$ e $0,45 \mathrm{~g} / 200 \mathrm{~mL}$ em cultivo de agitação.

Considerando ambas as formas de cultivo, estática e agitação, a maior produção de biomassa ocorreu entre 96h e 168h com volume médio de rendimento de 0,14g/200mL. Porém, o maior rendimento na produção de celulose ocorreu entre $24 \mathrm{~h}$ e $96 \mathrm{~h}$ com volume médio de 1,83g/200mL do fermentado.

A média da velocidade de formação da biomassa foi de $0,003 g \cdot h^{-1}$ e da celulose foi de 0,07 g.h ${ }^{-1}$. O rendimento médio, do processo de fermentação, da produção de biomassa em relação à formação da celulose foi de $0,042 \mathrm{~g}$.

A tabela 1 apresenta a produção de biomassa e celulose em diferentes tempos de cultivo. 
Tabela 1 - Produção de biomassa e celulose em diferentes tempos de cultivo

\begin{tabular}{|c|c|c|c|c|c|c|}
\hline \multirow[b]{2}{*}{ Ensaios } & \multicolumn{2}{|c|}{$24 \mathrm{~h}$} & \multicolumn{2}{|c|}{ 96h } & \multicolumn{2}{|c|}{$168 \mathrm{~h}$} \\
\hline & $\begin{array}{c}\text { Biomassa seca } \\
\text { g/200mL }\end{array}$ & $\begin{array}{l}\text { Celulose } \\
\text { g/200mL }\end{array}$ & $\begin{array}{c}\text { Biomassa seca } \\
\text { g/200mL }\end{array}$ & $\begin{array}{l}\text { Celulose } \\
\text { g/200mL }\end{array}$ & $\begin{array}{c}\text { Biomassa seca } \\
\text { g/200mL }\end{array}$ & $\begin{array}{l}\text { Celulose } \\
\text { g/200mL }\end{array}$ \\
\hline $1 *$ & 0,48 & 9,0 & 0,55 & 9,6 & 0,64 & 9,6 \\
\hline $2 *$ & 0,49 & 9,4 & 0,61 & 9,8 & 0,75 & 10,1 \\
\hline $3 *$ & 0,39 & 9,0 & 0,39 & 9,5 & 0,57 & 10,1 \\
\hline $4 *$ & 0,35 & 9,8 & 0,59 & 9,9 & 0,93 & 10,4 \\
\hline 5* & 0,32 & 9,9 & 0,58 & 10,4 & 0,81 & 10,4 \\
\hline 6* & 0,41 & 9,7 & 0,51 & 11,7 & 0,73 & 11,7 \\
\hline $7 *$ & 0,28 & 8,7 & 0,32 & 10,6 & 0,36 & 11,4 \\
\hline 8* & 0,36 & 10,3 & 0,52 & 10,9 & 0,57 & 12,4 \\
\hline $9 *$ & 0,33 & 8,6 & 0,53 & 9,2 & 0,66 & 10,6 \\
\hline $10 *$ & 0,57 & 10,7 & 0,86 & 12,3 & 0,89 & 16,9 \\
\hline $11^{*}$ & 0,61 & 10,8 & 0,63 & 11,1 & 0,71 & 11,8 \\
\hline $12 *$ & 0,36 & 10,3 & 0,52 & 12,7 & 0,75 & 12,8 \\
\hline $13^{*}$ & 0,42 & 9,9 & 0,50 & 10,3 & 0,59 & 10,8 \\
\hline $14^{*}$ & 0,35 & 11,9 & 0,55 & 12,4 & 0,96 & 14,4 \\
\hline $15^{*}$ & 0,29 & 10,6 & 0,32 & 9,4 & 0,36 & 10,5 \\
\hline $16^{*}$ & 0,28 & 10,4 & 0,36 & 10,9 & 0,41 & 12 \\
\hline 17 & 0,31 & 6,2 & 0,34 & 10,7 & 0,45 & 12,7 \\
\hline 18 & 0,30 & 6,2 & 0,34 & 10,7 & 0,50 & 12,7 \\
\hline 19 & 0,29 & 4,7 & 0,33 & 8,8 & 0,53 & 11,1 \\
\hline 20 & 0,32 & 10,9 & 0,39 & 10,4 & 0,66 & 13,1 \\
\hline 21 & 0,37 & 9,2 & 0,61 & 12,1 & 0,64 & 12,2 \\
\hline 22 & 0,29 & 9,4 & 0,43 & 13,1 & 0,62 & 13,1 \\
\hline 23 & 0,19 & 10,2 & 0,27 & 10,3 & 0,31 & 11,6 \\
\hline 24 & 0,40 & 11,1 & 0,41 & 13,1 & 0,45 & 13,1 \\
\hline 25 & 0,26 & 7,6 & 0,32 & 10,1 & 0,47 & 15,7 \\
\hline 26 & 0,25 & 12,1 & 0,30 & 14,1 & 0,59 & 17,1 \\
\hline 27 & 0,28 & 11,3 & 0,27 & 12,9 & 0,53 & 14,7 \\
\hline 28 & 0,32 & 12,1 & 0,35 & 12,9 & 0,45 & 17,1 \\
\hline 29 & 0,23 & 6,0 & 0,43 & 9,5 & 0,45 & 10,4 \\
\hline 30 & 0,27 & 7,3 & 0,32 & 11,2 & 0,45 & 11,2 \\
\hline 31 & 0,21 & 6,5 & 0,41 & 10,1 & 0,42 & 10,1 \\
\hline 32 & 0,27 & 8,3 & 0,48 & 8,9 & 0,49 & 11,9 \\
\hline
\end{tabular}

* Ensaios cultivados na forma estática.

Os gráficos, boxplot, de diagramas em caixa mostram a variabilidade dos dados, bem como possíveis outliers (valores extremos) existentes nos conjuntos de dados. Nesses pode-se ter uma visão geral do comportamento dos dados considerando o $\mathrm{Q}_{1}$ (primeiro quartil), a mediana, o $\mathrm{Q}_{3}$ (terceiro quartil) e a posição do valor médio comparados com essas três medidas. A seguir, a figura1 ilustra os diagramas em caixa dos dados referente ao rendimento da biomassa considerando os cultivos estático e agitação, nos tempos 24h, 96h e 168h. 
Figura 1 - Boxplot do cultivo estático e cultivo em agitação da biomassa seca em g/200 mL

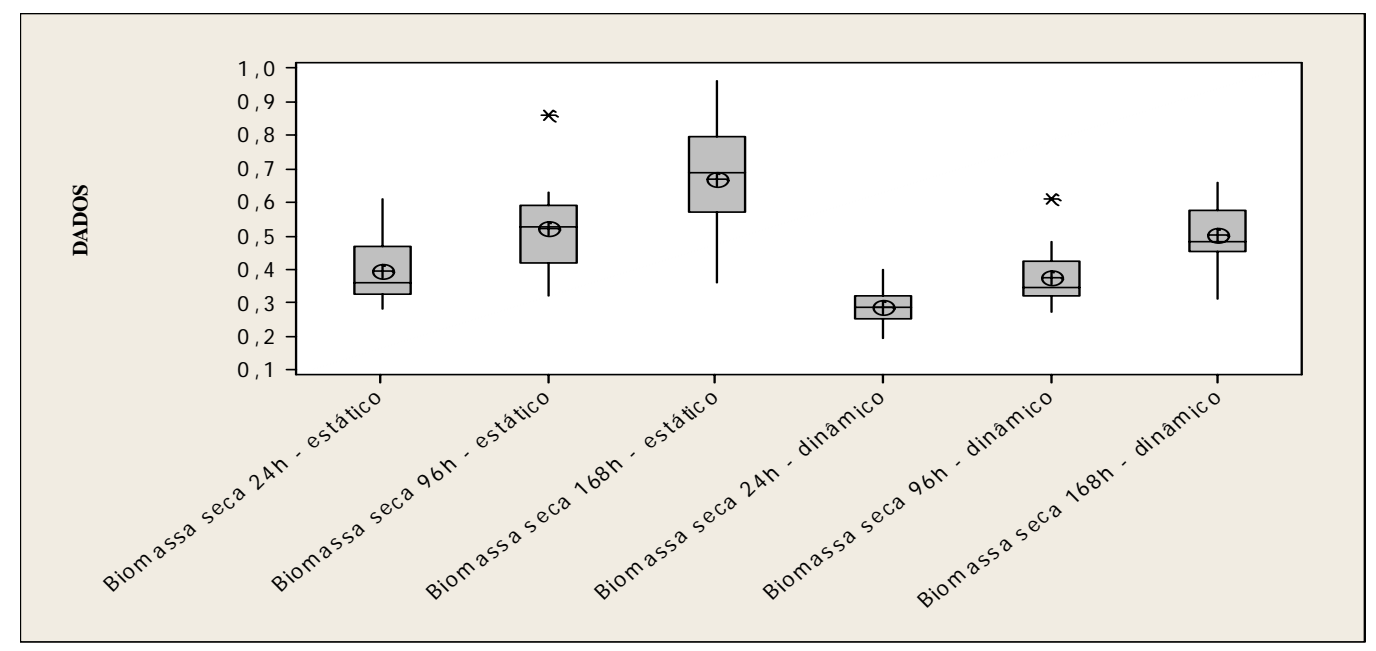

É imediata a observação que os valores médios estimados considerando o cultivo estático são maiores nos respectivos tempos de cultivo considerados. Porém, a variação destes dados entre si é maior quando comparada como a variação dos dados considerando o cultivo em agitação.

Na figura 1 observa-se a existência de dois outliers, ambos para o rendimento de biomassa seca considerando tempo 96 h, mas um em cultivo estático e outro em cultivo de agitação. Esses dois casos tratam-se, respectivamente, dos valores 0,86 g/200 mL (amostra 10) e 0,61 g/200 mL (amostra 21), o qual merece uma atenção especial, pois são apenas esses dois que se apresentam acima dos demais dados de forma significativa. Pode-se nesses dois casos verificar o que influenciou um rendimento significativamente maior quando comparados com as demais amostras. Por exemplo, tal influência pode ter sido motivada pela composição do meio de cultivo.

Nesse trabalho não foi possível tal investigação. Este fato será melhor detalhado em trabalhos futuros. Nos demais tempos não houve nenhum outliers detectado. Logo, tem-se que nenhum valor se destaca dos demais quanto sua magnitude.

A figura 2 ilustra os diagramas em caixa (boxplot) dos dados referentes ao rendimento da celulose considerando o cultivo estático e agitação, nos tempos 24h, 96h e 168h. 
Figura 2 - Boxplot do cultivo estático e cultivo em agitação da biomassa seca em g/200 mL

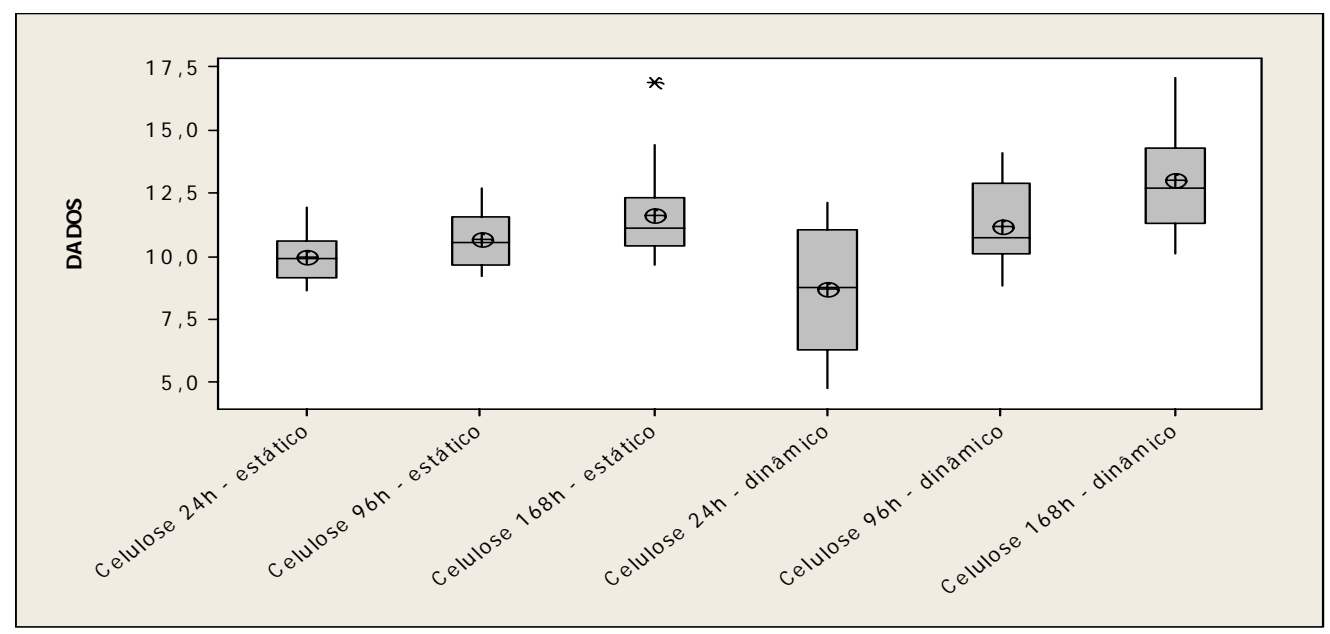

No caso do rendimento da celulose, as diferenças entre os valores médios estimados considerando o cultivo estático e o cultivo em agitação, são menores quando comparados com o que aconteceu com o rendimento da biomassa. Outro detalhe observado foi que, ao contrário do que aconteceu com o rendimento da biomassa seca, os rendimentos obtidos para celulose quando do cultivo estático são menos dispersos quando comparados com os rendimentos obtidos do cultivo em agitação. Um único outlier foi detectado, trata-se do valor 16,9 g/ 200mL obtido no cultivo estático em 168h. O mesmo dito na análise da figura 1, no que diz respeito o que influenciou este valor ser detectado como outlier, considere-se aqui.

Nos quadros 1 e 2 são apresentadas as estimativas de valores médios de rendimento, bem como as respectivas estimativas intervalares com 95\% de confiança. Por se tratar de amostras de tamanhos 16, para composição dos intervalos de confiança foi utilizado o valor crítico $t_{\alpha / 2}=2,132$ da distribuição de Student.

Quadro 1 - Estimativas para os valores médios de rendimento de biomassa e intervalo de confiança para tais estimativas em g/200 mL

\begin{tabular}{|c|c|c|c|c|c|c|}
\hline \multirow{2}{*}{ Variáveis } & \multicolumn{3}{|c|}{ Cultivo estático } & \multicolumn{3}{c|}{ Cultivo em agitação } \\
\cline { 2 - 7 } & $\begin{array}{c}\text { Valor } \\
\text { médio }\end{array}$ & $\begin{array}{c}\text { Desvio- } \\
\text { padrão }\end{array}$ & Intervalo de confiança & $\begin{array}{c}\text { Valor } \\
\text { médio }\end{array}$ & $\begin{array}{c}\text { Desvio- } \\
\text { padrão }\end{array}$ & $\begin{array}{c}\text { Intervalo de } \\
\text { confiança }\end{array}$ \\
\hline Biomassa seca 24h & 0,39 & 0,10 & $(0,34 ; 0,44)$ & 0,29 & 0,05 & $(0,26 ; 0,32)$ \\
\hline Biomassa seca 96h & 0,52 & 0,13 & $(0,45 ; 0,56)$ & 0,38 & 0,09 & $(0,33 ; 0,43)$ \\
\hline Biomassa seca 168h & 0,67 & 0,19 & $(0,57 ; 0,77)$ & 0,50 & 0,09 & $(0,45 ; 0,55)$ \\
\hline
\end{tabular}

De acordo com os resultados apresentados no quadro 1 o melhor rendimento médio, tanto para biomassa seca como para celulose, se obtém para um tempo de cultivo igual a 168 h. Porém, quando se utiliza o cultivo estático o resultado é melhor. Observa-se que não há interseção nas respectivas estimativas dos intervalos de confiança. Este fato reforça a idéia que o rendimento 
médio de biomassa quando se utiliza o cultivo estático realmente é maior de quando se utiliza o cultivo em agitação. Isto se repete para os outros dois tempos de cultivo.

Quadro 2 - Estimativas para os valores médios de rendimento de celulose e intervalo de confiança para tais estimativas em g/200 mL

\begin{tabular}{|c|c|c|c|c|c|c|}
\hline \multirow{2}{*}{ Variáveis } & \multicolumn{3}{|c|}{ Cultivo estático } & \multicolumn{3}{c|}{ Cultivo em agitação } \\
\cline { 2 - 7 } & $\begin{array}{c}\text { Valor } \\
\text { médio }\end{array}$ & Desvio-padrão & Intervalo de confiança & Valor médio & Desvio-padrão & Intervalo de confiança \\
\hline Celulose 24h & 9,94 & 0,88 & $(9,47 ; 10,41)$ & 8,69 & 2,41 & $(7,41 ; 9,97)$ \\
\hline Celulose 96h & 10,67 & 1,13 & $(10,07 ; 11,27)$ & 11,18 & 1,64 & $(10,31 ; 12,05)$ \\
\hline Celulose 168h & 11,62 & 1,87 & $(10,62 ; 12,62)$ & 12,99 & 2,16 & $(11,84 ; 14,14)$ \\
\hline
\end{tabular}

Observando os valores expostos no quadro 2 tem-se que o melhor rendimento de celulose, tanto para cultivo estático com para cultivo em agitação, é obtido com tempo de cultivo igual a 168h. Porém, não se pode afirmar que se obtém maior rendimento quando se utiliza o cultivo em agitação, pois há interseção ente as estimativas dos intervalos de confiança. Ainda, não parece haver diferença significativa entre os valores médios obtidos no rendimento da produção de celulose quando se compara os tempos de cultivo 96h e 168h. Este fato é observado de forma isolada, tanto para o cultivo estático como para o cultivo em agitação. É provável que ausência de diferença significativa entre os valores médios citados é devida a variabilidade que está havendo entre os dados analisados.

Ressalta-se que, tanto para o rendimento de biomassa seca como para o rendimento de celulose, a melhor estimativa para os verdadeiros valores médios são os valores médios amostrais obtidos e expostos nos quadros 1 e 2 . Porém, tem-se $95 \%$ de confiança que tais estimativas médias podem chegar até um máximo igual ao limite superior do respectivo intervalo de confiança.

A comparação entre as médias da produção de biomassa e celulose em cultivo estático e agitação está apresentada nos gráficos 1 e 2, respectivamente. Para o cultivo estático a produção de biomassa excedeu a produção de celulose em 168 horas. Entretanto, em 24 horas a produção de biomassa é menor que de celulose quando comparado com o cultivo em agitação, que apresentou uma maior produção de biomassa em 24 horas. A produção de celulose em cultivo de agitação somente excedeu a produção de biomassa em 96 horas.

Os gráficos 1 e 2 apresentam a produção de biomassa e celulose em cultivo estático e agitação, respectivamente. 


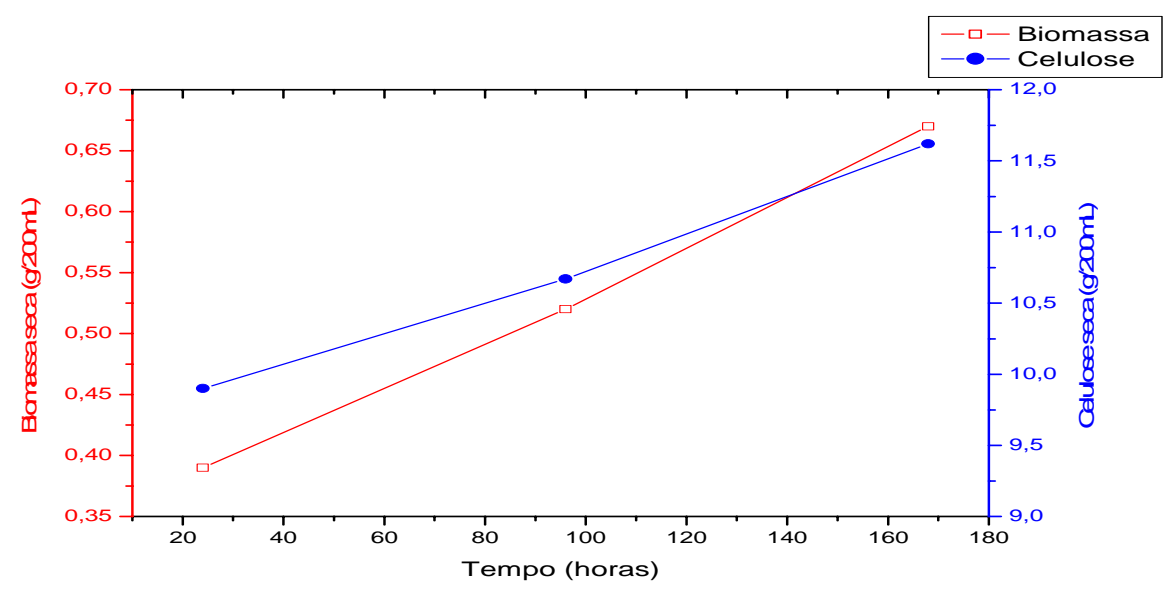

Gráfico 2 - Produção média de biomassa e celulose em cultivo de agitação

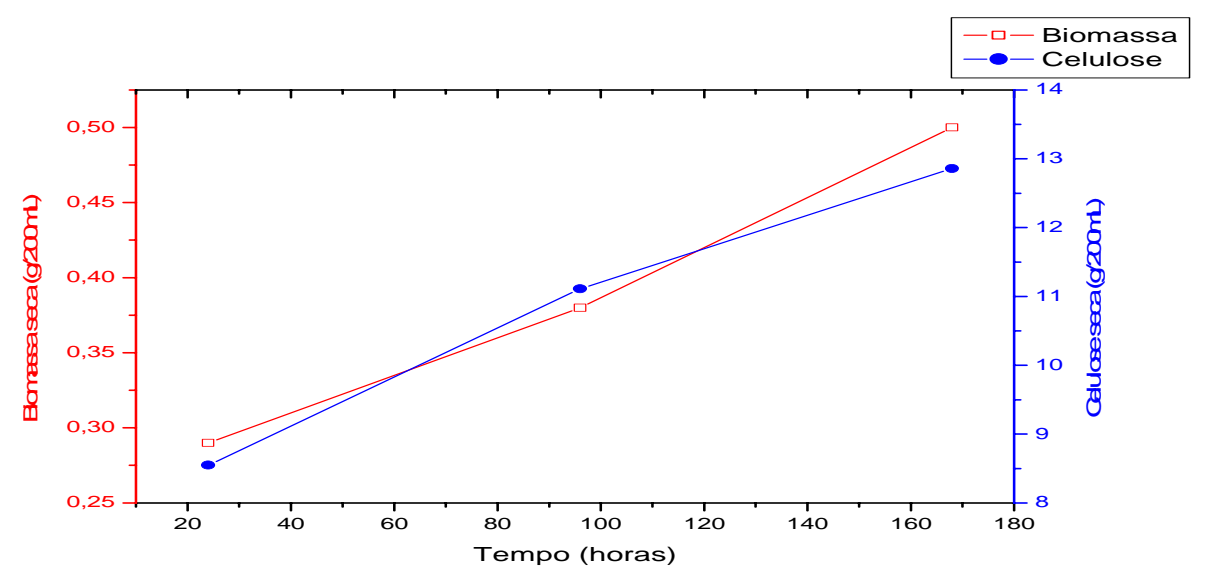

\section{Conclusão}

Um maior rendimento tanto de biomassa, quanto de celulose se obtém em um tempo de cultivo igual a 168 h. Porém, quando se utiliza o cultivo estático o resultado é melhor.

A maior produção de biomassa ocorreu em cultivo estático entre 96 e 168 horas. Já para a produção de celulose não se pode afirmar que se obtém maior rendimento quando se utiliza o cultivo em agitação, pois há interseção ente as estimativas dos intervalos de confiança. O microrganismo produz uma quantidade elevada de celulose nas primeiras 96 horas de fermentação seguida de um maior aumento na produção de biomassa.

\section{Abstract}

This research had as purpose checking the Acetobacter xylinum biomass growing (ATCC 23769) with the production of bacteria cellulose. The cultivation happened in the ripe coconut water $(200 \mathrm{ml})$ in the static form and in agitated $(100 \mathrm{rpm})$ and with addition of different salts solutions $\left(\mathrm{NH}_{4} \mathrm{PO}_{4}, \mathrm{KH}_{2} \mathrm{PO}_{4}, \mathrm{MgSO}_{4} 7 \mathrm{H}_{2} \mathrm{O}, \mathrm{Na}_{2} \mathrm{HPO}_{4}, \mathrm{FeSO}_{4}, \mathrm{H}_{3} \mathrm{BO}_{3}\right)$, making 32 essays. It were added $5 \%$ (v/v) or $0,06 \mathrm{~g}$ of dry biomass in the inoculums with incubation at $30^{\circ} \mathrm{C} \pm 2^{\circ} \mathrm{C} / 24 \mathrm{~h}, 96 \mathrm{~h}$ e $168 \mathrm{~h}$. For the removing of the biomass, the fermentation stock was centrifuged at $700 \mathrm{rpm} / 15 \mathrm{~min}$ at $4^{\circ} \mathrm{C}$, 
following by distillated water washing and after was taking to dehydration on a greenhouse at $50^{\circ} \mathrm{C} \pm 5^{\circ} \mathrm{C} / 24 \mathrm{~h}$ until constant mass. To the floating was added the proportion of etanol solvent $96^{\circ} \mathrm{GL}+$ acetone P.A (1:1:2) for the cellulose haste. After 24h of refrigeration it was made the new centrifuge in 30 min for the cellulose recovery. The hasty was washed with distillated water and dehydrated in a greenhouse at $50^{\circ} \mathrm{C} \pm 5^{\circ} \mathrm{C} / 24 \mathrm{~h}$ until constant mass. The bigger biomass production happened in static cultivation between 96 and 168 hours. For the cellulose production it cannot affirm that exist larger yield exists between the static cultivation or agitation. The microorganism makes a high amount of cellulose in the first 96 hours of ferment

Key-words: Acetobacter xylinum, cellulose, biomass

\section{Referências}

AQUINO, D. S. Produção de dextrana por novas linhagens de bactérias isoladas da cana-de-açúcar. Dissertação (Mestrado em Engenharia Química). Universidade Estadual de Campinas, UNICAMP, Campinas, 2006.

BERWANGER, A. L. D. S. Produção e caracterização de biopolímeros sintetizado por Sphingomonas capsulata. Dissertação (Mestrado em Engenharia de Alimentos). Universidade Regional Integrada do Alto Uruguai e das Missões, URI, Erechim, 2005.

FORNARI, R. C. G. Aproveitamento de Soro de Queijo para Produção de Goma Xantana. 2006, Dissertação (Mestrado em Engenharia de Alimentos) - Universidade Regional Integrada do Alto Uruguai e das Missões - URI, Campus de Erechim, Erechim-RS, 2006.

LEE JIN, W.; DENG, F.; YEOMANS, W. G.; ALLEN, A. L.; GROSS, R. A.; KAPLAN, D. L. Direct Incorporation of Glucosamine and $N$-Acetylglucosamine into Exopolymers by Gluconacetobacter xylinus (Acetobacter xylinum) ATCC 10245: Production of Chitosan-Cellulose and Chitin-Cellulose Exopolymers. Magazine APPLIED AND ENVIRONMENTAL MICROBIOLOGY, Sept. 2001, Vol. 67, No. 9 p.3970-3975.

MOREIRA, A. N.; DEL PINO, F. A.; VENDRUSCOLO, C. T. Estudo da produção de biopolímeros via enzimática através da inativação e lise celular e com células viáveis de Beijerinckia sp. 7070. Ciência e Tecnologia de Alimentos. v.23:2, p.300-305, 2003.

ROTTAVA, I. Seleção de linhagens de Xanthomonas sp. para produção de goma xantana. Dissertação (Mestrado Engenharia de Alimentos). Universidade Regional Integrada - URI, Erechim, 2005.

SILVA, L. L. Obtenção de cultura pura da bactéria Acetobacter xylinum a partir de água de côco para produção de fibras de celulose. Monografia apresentada no Curso Superior de Tecnologia em Alimentos, CEFET-PR Unidade Ponta Grossa, 2003.

\section{Dados do primeiro autor:}

Nome completo: Denise Milleo Almeida

Filiação institucional: Universidade Federal do Paraná $^{1}$ e Universidade Tecnológica Federal do Paraná Campus Ponta Grossa ${ }^{2}$

Função ou cargo ocupado: Doutoranda ${ }^{1}$; Professora ${ }^{2}$

Endereço completo para correspondência:Rua Zacarias Goes e Vasconcelos, 471 Bairro Uvaranas

Ponta Grossa-PR Brasil CEP 84020-220

Telefones para contato: (42) 3225-7608/91016808

e-mail:milleo@utfpr.edu.br 